\title{
EVALUASI PENGENDALIAN SISTEM INFORMASI PENJUALAN PADA PT. XYZ
}

\author{
Hari Setiabudi Husni; Tan Willy Tandra; Ade Anugrah \\ Jurusan Komputerisasi Akuntansi, Fakultas Ilmu Komputer, Bina Nusantara University \\ Jln. K.H Syahdan No. 9, Kemanggisan, Jakarta Barat 11480 \\ hari.setiabudi@binus.ac.id
}

\begin{abstract}
The objective of this research is to evaluate sales information system that is ongoing in PT XYZ and to identify problems in sales system and also to recommend a renovation suggestion towards sales application so it goes well, accurate, and high-quality. The research method in this paper is including important data and information collecting, literature study and field research: observation, interview and questionnaire. The result is identified that sales information system controlling in PT XYZ still needs development especially in upgrading system and recruitment in IT division to supervise application system to avoid potential risks that will influence targeting company objective.
\end{abstract}

Keywords: evaluation, information system, controlling, sales.

\begin{abstract}
ABSTRAK
Tujuan penelitian ini adalah mengevaluasi sistem informasi penjualan yang sedang berjalan pada PT $X Y Z$ dan mengidentifikasi permasalahan yang terjadi pada sistem penjualan ini serta merekomendasikan usulan perbaikan terhadap aplikasi penjualan agar dapat berjalan dengan baik, akurat dan berkualitas. Metode penelitian yang digunakan termasuk mengumpulkan data dan informasi yang dibutuhkan adalah studi kepustakaan dan penelitian lapangan: observasi, wawancara dan kuesioner. Hasilnya, diketahui bahwa pengendalian sistem informasi penjualan pada PT. XYZ masih perlu dilakukan peningkatan terutama dalam hal peng-upgrade-an sistem dan perekrutan divisi TI untuk mengawasi sistem aplikasi, untuk menghindari terjadinya risiko-risiko potensial yang akan mempengaruhi pencapaian tujuan perusahaan.
\end{abstract}

Kata kunci: evaluasi, sistem informasi, pengendalian, penjualan 


\section{PENDAHULUAN}

Perkembangan yang semakin pesat dan kompleks dalam dunia bisnis ditandai dengan makin meningkatnya kegiatan atau transaksi dan semakin meningkatnya kebutuhan pengelolaan keuangan, perlengkapan, sumber daya manusia maupun aspek perencanaan, pengendalian serta pengawasan.

Ketika organisasi menjadi semakin besar, maka informasi menjadi semakin penting sebagai salah satu alat bantu bagi manajer dalam menjalankan tugas serta fungsinya. informasi yang tepat waktu, lengkap dan relevan dibutuhkan untuk perencanaan dan pengambilan keputusan dalam rangka usaha untuk mencapai tujuan strategis perusahaan. Informasi juga meningkatkan hubungan perusahaan dengan lingkungannya yaitu pelangggan, pesaing, partner, pemasok , karyawan, lembaga keuangan, pemegang saham, masyarakat global dan pemerintah. Maka diperlukan sistem informasi yang dapat diandalkan, sehingga tidak menutup kemungkinan bahwa sistem informasi memiliki resiko, seperti kesalahan yang tidak disengaja dan penyalahgunaan oleh orang yang tidak berwenang. Dengan adanya resiko-resiko yang ditimbulkan dari sistem informasi tersebut, maka dilaksanakan evaluasi pengendalian sistem informasi.

Ada beberapa alasan diperlukannya evaluasi pengendalian sistem informasi : besarnya biaya dan kerugian jika data komputer hilang, biaya yang harus dikeluarkan bila informasi untuk bahan pengambilan keputusan salah, potensi kerugian jika terjadi kesalahan atau penyalahgunaan komputer, investasi yang tinggi dalam pemeliharaan hardware dan software, biaya yang tinggi untuk pelatihan karyawan, biaya yang tinggi bila komputer errors, perlunya dijaga privacy karena data yang tersimpan bersifat rahasia, dan agar perkembangan dan pertumbuhan komputerisasi dapat terkendali.

Control Objective for Information and related Technology (COBIT), adalah suatu panduan standar praktik manajemen teknologi informasi. COBIT dapat menyediakan seperangkat praktek yang dapat diterima pada umumnya karena dapat membantu para direktur, eksekutif dan manager meningkatkan nilai Teknologi Informasi dan mengecilkan resiko.

PT. XYZ bergerak di bidang distributor produk makanan dan minuman lokal dan impor merupakan salah satu perusahaan yang menggunakan sistem informasi untuk mendukung kegiatan operasionalnya.

\section{Landasan Teori}

\section{Pengertian Sistem Informasi}

Menurut James O'Brien (2005), sistem informasi adalah mengorganisasi, mengatur personil, perangkat keras, perangkat lunak, jaringan komunikasi dan sumber data yang dikumpulkan, disalurkan dan membagi informasi dalam sebuah organisasi.

\section{Sistem Informasi Penjualan}

Sistem informasi penjualan adalah suatu sistem informasi yang mengorganisasikan serangkaian prosedur dan metode yang dirancang untuk menghasilkan, menganalisa, menyebarkan dan memperoleh informasi guna mendukung pengambilan keputusan di bidang penjualan.

\section{Pengertian Evaluasi}

Evaluasi adalah suatu proses untuk menyediakan informasi mengenai hasil penilaian atas permasalahan yang ditemukan. 


\section{Pengertian Evaluasi Pengendalian Sistem Informasi}

Evaluasi Pengendalian Sistem Informasi merupakan suatu proses untuk menyediakan informasi mengenai hasil penilaian atas permasalahan yang ditemukan untuk melakukan pencegahan, pendeteksian, atau perbaikan kelemahan terhadap serangkaian komponen-komponen yang bekerja sama untuk mengumpulkan, mengolah, menyimpan dan mendistribusikan informasi yang digunakan sebagai alat untuk mencapai tujuan tertentu.

\section{Tahapan Evaluasi Pengendalian Sistem Informasi}

Langkah-langkah dalam melakukan evaluasi sistem informasi adalah merencanakan evaluasi, mengevaluasi bukti-bukti pendukung, dan mengkomunikasikan hasil evaluasi. Tujuan perencanaan evaluasi adalah untuk menetapkan mengapa, bagaimana, kapan, dan oleh siapa proses evaluasi akan dilaksanakan. Langkah dalam perencanaan audit adalah: (1) menetapkan ruang lingkup dan tujuan evaluasi; (2) mengorganisir tim pengevaluasi; (3) mengembangkan pengetahuan tentang operasional bisnis; (4) mengidentifikasi faktor risiko; (5) menyiapkan program audit; (6) mengumpulkan buktibukti pendukung.

Metode yang dapat digunakan untuk mengumpulkan bukti-bukti pendukung antara lain: (1) observasi, mengamati kegiatan operasional; (2) mereview dokumentasi; (3) berdiskusi dengan para karyawan mengenai pekerjaan mereka dan bagaimana untuk melaksanakan prosedur tertentu; (4) kuisioner untuk mengumpulkan data mengenai sistem; (5) pemeriksaan fisik terhadap jumlah dan kondisi tangible asset. Dalam mengevaluasi bukti-bukti pendukung, auditor mengevaluasi bukti pendukung yang dikumpulkan dengan dasar tujuan evaluasi dan memutuskan apakah bukti tersebut mendukung kesimpulan atau tidak. Auditor juga menilai kualitas pengendalian internal, menilai reliabilitas informasi yang didapat, menilai kinerja operasi, menentukan kebutuhan untuk menambah bukti, menentukan faktor resiko, menentukan faktor materialitas, dan mendokumentasikan temuantemuan. Tahapan terakhir yaitu mengkomunikasikan hasil evaluasi. Tim evaluasi menyiapkan laporan tertulis yang meringkas temuan-temuan dan rekomendasi dengan referensi untuk mendukung bukti hasil evaluasi dalam lembar kerja. Laporan ini disajikan untuk manajemen dan pihak lain yang terkait.

\section{Standar Evaluasi}

\section{Pengertian CoBIT}

CoBIT adalah sekumpulan dokumentasi best practices untuk IT governance yang dapat membantu auditor, pengguna (user), dan manajemen, untuk menjembatani gap antara risiko bisnis, kebutuhan kontrol dan masalah-masalah teknis TI. CoBIT bermanfaat bagi auditor karena merupakan teknik yang dapat membantu dalam identifikasi IT control issues. CoBIT berguna bagi para IT user karena memperoleh keyakinan atas kehandalan sistem aplikasi yang dipergunakan. Sedangkan para manajer memperoleh manfaat dalam keputusan investasi di bidang TI serta infrastrukturnya, menyusun strategic IT plan, menentukan informasi arsitektur, dan keputusan atas procurement (pengadaan/pembelian) mesin. Disamping itu, dengan keterandalan sistem informasi yang ada pada perusahaan diharapkan berbagai keputusan bisnis dapat didasarkan atas informasi yang ada. Berdasarkan CobIT 4.1, CobIT meliputi control objectives, control practices, audit guidelines, management guidelines.

\section{Control Objectives}

Level tertinggi dan secara umum memberikan pernyataan pengendalian minimal yang terbaik. CobIT menganggap desain dan implementasi pengendalian aplikasi otomatis menjadi tanggung jawab TI, mencakup bagian akuisisi dan implementasi, berdasarkan kebutuhan bisnis yang ditetapkan dalam 
standar CobIT. Control Objectives terdiri atas 4 tujuan pengendalian tingkat tinggi yang tercermin dalam 4 domain, yaitu planning and organization, acquisition and implementation, delivery and support, monitoring and evaluation.

\section{Planning and Organization}

Domain ini meliputi strategi dan taktik yang berkonsentrasi pada identifikasi cara TI bisa menjadi kontribusi terbaik untuk mencapai tujuan bisnis. Selanjutnya, realisasi visi strategi perlu direncanakan, dikomunikasikan, dan diatur dalam pandangan yang berbeda. Akhirnya, suatu organisasi yang sebenarnya akan baik apabila prasarana teknologi diletakkan pada tempatnya. Hal-hal yang diperhatikan dalam perencanaan dan organisasi adalah: PO1 mendefinisikan rencana TI strategis, PO2 mendefinisikan arsitektur informasi, PO3 menentukan arah teknologi, PO4 mendefinisikan proses, organisasi dan hubungan TI, PO5 mengatur investasi TI, PO6 mengkomunikasikan tujuan dan arahan manajemen, PO7 mengatur SDM (Sumber Daya Manusia) di bidang TI, PO8 mengatur kualitas, PO9 menilai dan mengatur resiko TI, PO10 mengatur proyek.

\section{Acquisition and Implementation}

Strategi TI, solusi TI perlu untuk di identifikasi, dikembangkan atau diperoleh seperti halnya sistem yang terintegrasi dan diterapkan ke dalam proses bisnis. Perubahan dan pemeliharaan sistem yang sedang berjalan mencakup area untuk membuat solusi yang selanjutnya digunakan untuk memenuhi tujuan bisnis. Hal-hal yang diperhatikan dalam perolehan dan implementasi adalah: AI1 mengidentifikasi solusi otomatis, AI2 memperoleh dan merawat software aplikasi, AI3 memperoleh dan merawat infrastruktur teknologi, AI4 memungkinkan operasi dan penggunaan; AI5 memperoleh sumber daya TI, AI6 mengatur perubahan, dan AI7 meng-install dan mengakuisisi solusi dan perubahan.

\section{Delivery and Support}

Daerah ini memiliki kaitan dengan penyampaian dalam penyerahan kebutuhan layanan, manajemen keamanan, layanan pendukung untuk pengguna dan manajemen data serta fasilitas operasional. Hal-hal yang diperbaiki dalam pengiriman dan pendukung adalah: DS1 mendefinisikan dan mengatur tingkat layanan, DS2 mengatur pelayanan pihak ketiga, DS3 mengatur kinerja dan kapasitas, DS4 memastikan pelayanan berkelanjutan, DS5 memastikan keamanan sistem, DS6 mengidentifikasi dan mengalokasikan biaya, DS7 mendidik dan melatih pemakai, DS8 mengatur service desk dan peristiwa, DS9 mengatur konfigurasi, DS10 mengatur masalah, DS11 mengatur data, DS12 mengatur lingkungan fisik, DS13 mengatur operasi.

\section{Monitoring and Evaluation}

Yaitu semua proses TI yang perlu dinilai secara teratur agar kualitas dan kelengkapannya berdasarkan pada syarat kontrol. Hal-hal yang diperhatikan dalam pemantuan dan evaluasi adalah: ME1 memonitor dan mengevaluasi kinerja TI, ME2 memonitor dan mengevaluasi pengendalian internal, ME3 memastikan kepatuhan pada peraturan, ME4 menyediakan penguasaan TI.

\section{Control Practices}

Prinsip-prinsip pengerjaan dan bagaimana mengimplementasikan pedoman untuk tujuan pengendalian. 


\section{Audit Guidelines}

Pedoman untuk setiap lingkup control mengenai bagaimana untuk memperoleh pengertian, mengevaluasi setiap pengendalian, mengakses ketaatan, dan mengukur risiko pengendalian yang sedang dicari untuk membantu para auditor dalam memberikan saran perbaikan.

\section{Management Guidelines}

Pedoman mengenai bagaiman mengkases dan menngkatkan kinerja proses TI, menggunakan maturity model, matriks, dan CSF (Critical Success Factor). Berisi arahan, baik secara umum maupun spesifik, mengenai apa saja yang harus dilakukan, terutama agar dapat menjawab pertanyaanpertanyaan berikut: (1) sejauh mana Anda (TI) harus bergerak, dan apakah biaya TI yang dikeluarkan sesuai dengan manfaat yang dihasilkannya; (2) apa saja indikator untuk suatu kinerja yang bagus?; (3) apa saja faktor atau kondisi yang harus diciptakan agar dapat mencapai sukses (critical success factors); (4) apa saja risiko-risiko yang timbul, apabila kita tidak mencapai sasaran yang ditentukan; (5) bagaimana dengan perusahaan lainnya - apa yang mereka lakukan; (6) bagaimana Anda mengukur keberhasilan dan bagaimana pula membandingkannya.

CoBIT framework memasukkan juga hal-hal seperti model maturity, Critical Success Factor (CSF), Key Goals Indicators (KGI), dan Key Performance Indicators (KPI).

\section{Maturity Models}

Untuk memetakan status maturity proses-proses TI (dalam skala 0 - 5) dibandingkan dengan the best in the class in the Industry dan juga International best practices. Skala tersebut yaitu (1) Skala 0 - Not Existance, karena perusahaan tidak menyadari pentingnya membuat perencanaan strategis di bidang teknologi informasi, dalam skala ini penting untuk dilakukan evaluasi pengendalian dan dijadikan sebagai temuan yang penting; (2) Skala 1 - Initial, adanya fakta-fakta bahwa perusahaan telah menyadari akan pentingnya pembuatan perencanaan strategis di bidang teknologi informasi. Namun, tidak ada proses yang distandarisasi; perencanaan, perancangan dan manajemen masih belum terorganisir dengan baik. Dalam skala ini keperluan untuk dijadikan temuan tidak diutamakan, karena tingkat kemungkinan terjadinya resiko tidak sebesar skala nol; (3) Skala 2 - Repeatable, perusahaan telah menetapkan prosedur untuk dipatuhi oleh karyawan, namun belum dikomunikasikan dan belum adanya pemberian latihan formal kepada setiap karyawan mengenai prosedur; dan tanggung jawab diberikan sepenuhnya kepada individu sehingga pemberian kepercayaan sepenuhnya kemungkinan dapat terjadi penyalahgunaan; (4) Skala 3 - Defined, seluruh proses telah didokumentasikan dan telah dikomunikasikan, serta dilaksanakan berdasarkan metode pengembangan sistem komputerisasi yang baik, namun belum ada proses evaluasi terhadap sistem tersebut, sehingga masih ada kemungkinan terjadinya penyimpangan; (5) Skala 4 - Managed, Proses komputerisasi telah dapat dimonitor dan dievaluasi dengan baik, manajemen proyek pengembangan sistem komputerisasi sudah dijalankan dengan lebih terorganisir; (6) Skala 5 - Optimised, Best Practices (pedoman terbaik) telah diikuti dan diotomatisasi pada sistem berdasarkan proses yang terencana, terorganisir dan menggunakan metodologi yang tepat.

\section{Critical Success Factors (CSFs)}

Arahan implementasi bagi manajemen agar dapat melakukan kontrol atas proses TI.

\section{Key Goal Indicators (KGIs)}

Kinerja proses-proses TI sehubungan dengan business requirements. 


\section{Key Performance Indicators (KPIs)}

Kinerja proses-proses TI sehubungan dengan process goals.

\section{Kriteria Kerja CoBIT}

Kriteria kerja CoBIT terdiri dari: (1) efektivitas (effectiveness), dalam memperoleh informasi harus relevan dan terkait dengan proses bisnis, serta disampaikan dengan tepat waktu, benar, konsisten, dan dapat dimanfaatkan; (2) efisiensi (efficiency), menekankan pada provision of Information yang optimal (paling produktif dan ekonomis) dalam menggunakan sumber daya; (3) kerahasiaan (confidentialty), memfokuskan pada proteksi terhadap informasi yang penting dari orang yang tidak memiliki hak otorisasi; (4) integritas (integrity), berkaitan dengan keakuratan dan kelengkapan informasi, sebagai kebenaran yang sesuai dengan harapan dan nilai bisnis; (5) ketersediaan (availability), berkaitan dengan ketersediaan informasi yang dibutuhkan oleh bisnis pada saat sekarang dan akan datang; (6) kepatuhan (compliance), menekankan pada ketaatan perusahaan terhadap hukum, peraturan, dan kontrak yang telah dibuat; (7) keandalan (reliability), berkaitan dengan kesesuaian informasi bagi manajemen dalam mengoperasikan perusahaan dan penyusunan laporan keuangan.

\section{METODE}

Metode penelitian yang digunakan dalam pengumpulan data-data untuk penulisan skripsi ini adalah (1) studi kepustakaan, penelitian ini dilakukan dengan cara mencari dan mengumpulkan data, sumber informasi dan bahan-bahan yang diperoleh dari buku, literatur, artikel; (2) studi lapangan, studi ini dilakukan dengan mendapatkan data secara langsung dari obyek penelitian.; (3) wawancara, melakukan tanya jawab dengan pihak yang terkait untuk mendapatkan informasi dan data-data yang dibutuhkan; (4) observasi, melakukan pengamatan secara langsung pada lingkungan serta penerapan sistem informasi pada perusahaan dan penggunaan sistem informasi oleh user yang terkait untuk mengetahui fungsi-fungsi yang terdapat dalam sistem informasi tersebut; (5) kuisioner, mengumpulkan data-data dengan cara membuat daftar pertanyaan untuk diajukan kepada pihak yang bersangkutan untuk memperoleh gambaran umum dan arus bisnis perusahaan, kuesioner dilakukan agar dapat memperoleh jawaban yang lebih terarah dan jujur dari hasil wawancara tersebut; (6) testing atau pengujian, pengumpulan data dengan melakukan pengujian langsung terhadap sistem informasi persediaan.

\section{HASIL DAN PEMBAHASAN}

\section{Gambaran Sistem Penjualan PT. XYZ}

Dapat dilihat pada Gambar 1.

\section{Evaluasi Pengendalian Sistem Informasi Penjualan}

Berikut ini (Tabel 1) adalah hasil analisis berupa hasil kuisioner, wawancara dan observasi mengenai plan and organise, acquire and implement, deliver and support, dan monitor and evaluate, dan temuan kelemahan-kelemahan dari pengendalian sistem informasi penjualan pada PT. XYZ, serta rekomendasi yang dapat membantu menginspirasi perusahaan dalam melakukan perbaikan. Berikut adalah tabel yang memuat mengenai temuan, risiko dan rekomendasi. 


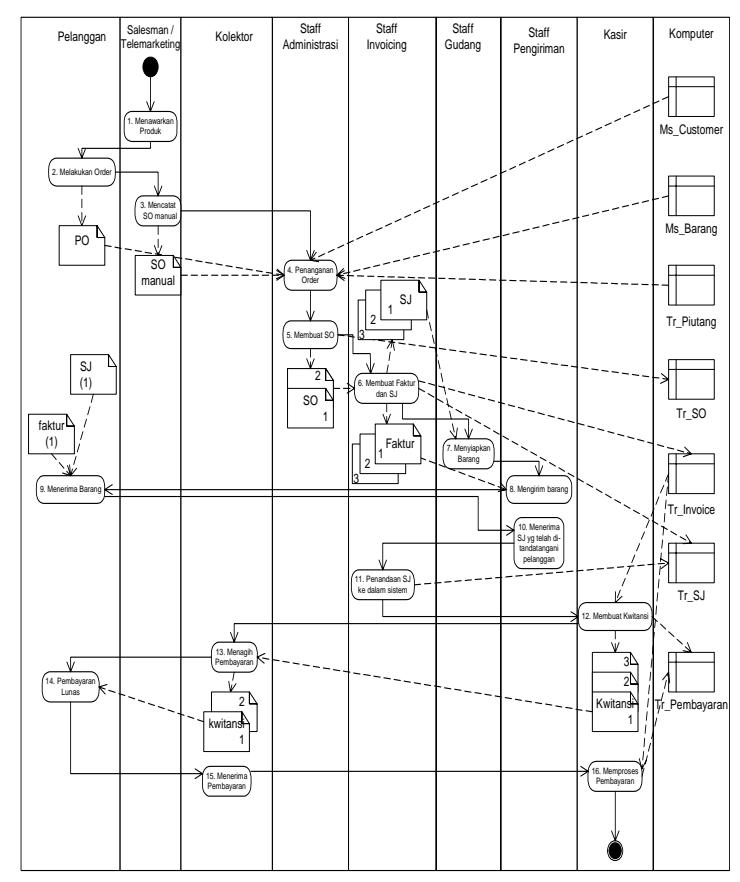

Gambar 1 Overview Activity Diagram Penjualan

Tabel 1 Hasil Evaluasi

\begin{tabular}{|c|c|c|c|}
\hline No. & Temuan & Risiko & Rekomendasi \\
\hline 1. & $\begin{array}{lc}\text { Belum adanya } & \text { peng- } \\
\text { upgrade-an } & \text { sistem } \\
\text { aplikasi secara berkala }\end{array}$ & $\begin{array}{l}\text { Sistem yang digunakan tidak up-to- } \\
\text { date sehingga menjadi ketinggalan } \\
\text { zaman, dan sulit untuk beralih ke } \\
\text { sistem baru. Dan bagi user baru akan } \\
\text { mengalami kesulitan dalam } \\
\text { menjalankan perintah-perintah } \\
\text { dengan menggunakan tombol-tombol } \\
\text { keyboard karena sistem operasi } \\
\text { masih menggunakan under dos, } \\
\text { sehingga kurang efisien dalam hal } \\
\text { waktu untuk memahami penggunaan } \\
\text { sistem aplikasi. }\end{array}$ & $\begin{array}{l}\text { Sebaiknya perusahaan melakukan } \\
\text { peng-upgrade-an sistem baru yang } \\
\text { lebih fleksibel, seperti aplikasi } \\
\text { software dengan menggunakan } \\
\text { VB.net. dan memudahkan bagi user } \\
\text { baru untuk menggunakan aplikasi, } \\
\text { serta mendukung efisiensi waktu } \\
\text { dalam hal pelatihan. }\end{array}$ \\
\hline 2. & $\begin{array}{l}\text { Belum ada staff khusus } \\
\text { bagian TI dalam struktur } \\
\text { organisasi perusahaan. }\end{array}$ & $\begin{array}{l}\text { Jika terjadi kerusakan sulit untuk } \\
\text { mengatasinya dan maintenance } \\
\text { terhadap TI menjadi tidak memadai. }\end{array}$ & $\begin{array}{l}\text { Mengingat kegiatan perusahaan } \\
\text { sudah semakin berkembang, maka } \\
\text { keberadaan staff TI menjadi sangat } \\
\text { berguna bagi perusahaan. } \\
\text { Diperlukan staff TI yang kompeten, } \\
\text { dan pengetahuan yang luas } \\
\text { mengenai dunia TI, sebaiknya } \\
\text { merupakan lulusan sarjana } \\
\text { komputer. }\end{array}$ \\
\hline 3. & $\begin{array}{l}\text { Belum ada perencanaan } \\
\text { untuk melakukan review } \\
\text { terhadap kinerja dan } \\
\text { kemampuan sumber daya } \\
\text { TI. }\end{array}$ & $\begin{array}{lrr}\text { Sulit bagi } & \text { perusahaan } & \text { untuk } \\
\text { menentukan } & \text { seberapa } & \text { besar } \\
\text { efektifitas TI terhadap } & \text { tujuan } \\
\text { perusahaan dan sulit untuk } \\
\text { menyadari secara dini kemungkinan } \\
\text { adanya kerugian yang tidak } \\
\text { terdeteksi akibat tidak adanya }\end{array}$ & $\begin{array}{l}\text { Sebaiknya dilakukan perencanaan } \\
\text { monitoring terhadap kinerja dan } \\
\text { kemampuan TI dengan melakukan } \\
\text { pencatatan berupa indikator- } \\
\text { indikator berupa indikator jumlah } \\
\text { kesalahan, indikator jumlah } \\
\text { keluhan, indikator kemajuan dalam }\end{array}$ \\
\hline
\end{tabular}




\begin{tabular}{|c|c|c|c|}
\hline & & $\begin{array}{l}\text { tindakan perencanaan } \\
\text { kinerja dan kemampuan TI. }\end{array}$ & $\begin{array}{l}\text { hal kecepatan waktu. Perusahaan } \\
\text { dapat pula melakukan pengukuran } \\
\text { cost benefit untuk mengukur } \\
\text { manfaat TI yang bersifat intagible. }\end{array}$ \\
\hline 4. & $\begin{array}{l}\text { perusahaan tidak } \\
\text { melakukan pencatatan } \\
\text { terhadap masalah-masalah } \\
\text { yang ditimbulkan TI dan } \\
\text { cara masalah tersebut } \\
\text { diatasi. }\end{array}$ & $\begin{array}{l}\text { Kemungkinan jika terjadi kesalahan } \\
\text { akan memakan waktu lama, sehingga } \\
\text { kurang efisien dalam hal waktu. }\end{array}$ & $\begin{array}{l}\text { Sebaiknya perusahaan melakukan } \\
\text { pencatatan terhadap setiap masalah } \\
\text { TI yang pernah dihadapi } \\
\text { perusahaan dan cara untuk } \\
\text { mengatasinya. Pencatatan dapat } \\
\text { pula berupa catatan indikator } \\
\text { terjadinya kesalahan oleh pihak } \\
\text { bagian TI (jika ada), atau pihak lain } \\
\text { yang sering menangani hal tersebut. }\end{array}$ \\
\hline 5. & $\begin{array}{l}\text { Password tidak diganti } \\
\text { secara berkala. }\end{array}$ & $\begin{array}{l}\text { Dapat mengakibatkan data dapat } \\
\text { dimodifikasi oleh pihak yang tidak } \\
\text { berwenang, sehingga integritas data, } \\
\text { kerahasiaan, dan ketersediaan } \\
\text { informasi tidak terjamin. }\end{array}$ & $\begin{array}{l}\text { Password sebaiknya diganti secara } \\
\text { rutin maksimal } 2 \text { bulan sekali agar } \\
\text { tidak terjadi penyalahgunaan akses } \\
\text { sistem oleh pihak yang tidak } \\
\text { berwenang. Sebaiknya diterapkan } \\
\text { aplikasi SI yang memberlakukan } \\
\text { adanya expired jika password tidak } \\
\text { diganti dalam kurun waktu tertentu, } \\
\text { dan hal ini perlu diawasi oleh pihak } \\
\text { yang dapat memberikan sangsi jika } \\
\text { password tidak diganti secara rutin. }\end{array}$ \\
\hline 6. & $\begin{array}{l}\text { Tidak ada } \text { penetapan } \\
\text { target kinerja mengenai } \\
\text { kemajuan target kinerja } \\
\text { TI }\end{array}$ & $\begin{array}{l}\text { Menyebabkan karyawan perusahaan } \\
\text { tidak bekerja secara optimal karena } \\
\text { tidak adanya motivasi atau target } \\
\text { yang harus dipenuhi }\end{array}$ & $\begin{array}{l}\text { Sebaiknya perusahaan membuat } \\
\text { target terhadap kinerja TI-nya } \\
\text { berupa pencatatan indikator kinerja } \\
\text { karyawan terhadap TI untuk } \\
\text { menetapkan standar kemajuan } \\
\text { kinerja TI. }\end{array}$ \\
\hline 7. & $\begin{array}{l}\text { Monitoring terhadap TI } \\
\text { belum memadai karena } \\
\text { terjadinya rangkap antara } \\
\text { tugas sebagai manager } \\
\text { finance accounting } \\
\text { dengan tugas sebagai } \\
\text { staff TI }\end{array}$ & $\begin{array}{l}\text { Kemungkinan dapat terjadi } \\
\text { ketidakefektifan dalam pekerjaan, } \\
\text { dan kecurangan dapat saja terjadi. }\end{array}$ & $\begin{array}{l}\text { Sebaiknya perusahaan } \\
\text { menggunakan staff khusus untuk } \\
\text { mengawasi TI, setidaknya untuk } \\
\text { melakukan pemisahan fungsi untuk } \\
\text { menghindari ketidakefektifan kerja } \\
\text { dan kecurangan yang mungkin saja } \\
\text { dapat terjadi. }\end{array}$ \\
\hline
\end{tabular}

\section{SIMPULAN}

Setelah melakukan evaluasi pengendalian sistem informasi penjualan pada PT. XYZ dengan menggunakan standar COBIT yang mengacu pada 4 domain, yaitu plan and organise, acquire and implement, deliver and support, dan monitor and evaluate, maka dapat diperoleh kesimpulan bahwa PO (Plan and Organise) PT. XYZ adalah sudah cukup baik, namun tidak ada divisi TI untuk menangani kerusakan dan pemeliharaan TI sehingga menjadi kurang memadai. AI (Acquire and Implement) PT. XYZ adalah sudah cukup baik, hanya saja operating system yang digunakan perusahaan adalah Under-Dos sehingga kinerja TI pun tidak mengikuti perkembangan jaman dan sulit dalam pengoperasian komputernya karena hanya menggunakan keyboard dan tidak ada mouse sebagai alat bantu menjalankan perintah-perintah dalam komputer. Dari segi user friendly sudah memadai karena karyawan lama sudah terbiasa dalam penggunaan aplikasi. DS (Deliver and Support) PT. XYZ adalah masih kurang baik karena keamanan sistem masih belum terjamin, seperti password yang tidak diganti secara berkala yang dapat mengakibatkan data dapat dimodifikasi oleh pihak yang tidak berwenang, dan tidak adanya pencatatan terhadap masalah-masalah yang ditimbulkan TI sehingga sulit untuk mendeteksi dan memproteksi kesalahan atau penyalahgunaan sistem. ME (Monitor and 
Evaluate) PT. XYZ yaitu masih kurang baik karena tidak adanya penetapan target mengenai kemajuan target kinerja TI itu sendiri dan perusahaan tidak melakukan monitoring dan evaluasi terhadap keuntungan yang didapat sehubungan dengan TI yang digunakan.

Berdasarkan simpulan di atas, maka saran yang dapat diberikan sebagai tindak lanjut atas pelaksanaan audit sistem informasi penjualan adalah untuk PO (Plan and Organise) pada PT Unggultama Indonesia Mengingat kegiatan perusahaan sudah semakin berkembang, maka keberadaan staf TI menjadi sangat berguna bagi perusahaan dalam hal peng-upgrade-an system, monitoring, dan pemeliharaan sistem aplikasi dan perangkat komputer lainnya. Oleh karena itu, diperlukan staf TI yang kompeten, dan pengetahuan yang luas mengenai dunia TI, sebaiknya merupakan lulusan sarjana komputer. Untuk AI (Acquire and Implement) pada PT. XYZ sebaiknya perusahaan melakukan pengupgrade-an sistem baru yang lebih fleksibel, seperti aplikasi software dengan menggunakan VB.net.

Untuk DS (Deliver and Support) pada PT. XYZ, yaitu Sebaiknya password diganti secara rutin maksimal 2 (dua) bulan sekali agar tidak terjadi penyalahgunaan akses sistem oleh pihak yang tidak berwenang. Sebaiknya diterapkan aplikasi SI yang memberlakukan adanya expired jika password tidak diganti dalam kurun waktu tertentu, dan hal ini perlu diawasi oleh pihak yang dapat memberikan sanksi jika password tidak diganti secara rutin. Dan sebaiknya perusahaan melakukan pencatatan terhadap setiap masalah TI yang pernah dihadapi perusahaan dan cara untuk mengatasinya. Pencatatan dapat pula berupa catatan indikator terjadinya kesalahan oleh pihak bagian TI (jika ada), atau pihak lain yang sering menangani hal tersebut. Untuk ME (Monitor and Evaluate) pada PT. XYZ Sebaiknya perusahaan membuat target terhadap kinerja TI-nya berupa pencatatan indikator penghasilan atau keuntungan bisnis terhadap TI untuk menetapkan standar kemajuan ketika TI diterapkan di dalam perusahaan. Target kinerja ini dapat ditentukan dari seberapa cepat perusahaan menangani proses transaksi penjualan, misalnya penghasilan yang didapat selama sebulan sebelum menggunakan atau meng-upgrade sistem dan sesudah menggunakan atau meng-upgrade sistem baru, namun kondisi dalam penentuan jumlah penghasilan harus ditentukan dari kondisi secara global yang stabil, misalnya kondisi krisis global dapat mempengaruhi jumlah penjualan perusahaan, sehingga tidak bisa dijadikan patokan dalam hal penentuan target penghasilan bisnis dengan kinerja TI.

\section{DAFTAR PUSTAKA}

Gondodiyoto, S. (2007). Audit Sistem Informasi + Pendekatan COBIT. Jakarta: PT. Mitra Wacana Media.

Hall, J. A. (2001). Sistem Informasi Akuntansi (1st ed.). (Jusuf, A.A., Terj.). Jakarta: Salemba Empat.

Husein, U.(2005). Evaluasi Kinerja Perusahaan. Jakarta: Gramedia Pustaka Utama.

IT Governance Institute. (2007). COBIT 4.1. United State of America.

Jones, F. L., \& Rama, D. V. (2003). Accounting Information System, a Business Process Approach. South-Western: Thomson.

Kamus Besar Bahasa Indonesia. (2002). Jakarta.

O’Brien, J. A.(2005). Introduction to Information Systems (12th ed.). Jakarta: Salemba Empat.

Robbins, P. S., \& Coulter, M. (1999). Manajemen (6th ed.). (Drs. T. Hermaya, Terj.). Jakarta: Prenhallindo. 
Romney, M. B.,.\& Steinbart, P. J. (2003). Accounting Information System (9th ed.). New Jersey: Pearson Education International.

Sugiyono. (2006). Metode Penelitian Bisnis (6th ed.). Bandung: Alfabeta.

Turban, E., Rainer, R.K., \& Potter, R. E. (2003). Information Technology (2nd ed.). John Willey \& Sons.

Weber, R. (1999). Information System Control and Audit. New Jersey: Prentice-Hall.

Whittington, O. R., \& Peny, K. (2001). Principles of Auditing and Other Assurance Services. McGraw-Hill.

Wilkinson, C. R., \& Wing, W. O. (2000). Accounting Information System: Essenstial Concepts and Applications. USA: John Wiley \& Sons. 